\title{
La Unión Europea veinte años después de Maastricht: hitos y retos*
}

\author{
Igor Filibi \\ Profesor de Relaciones Internacionales \\ Universidad del País Vasco (UPV/EHU)
}

\begin{abstract}
Sumario: I. Introducción.-II. Integración europea y paz: la paz estructural. - III. Del modelo tecnocrático al debate político: la Unión Europea. 1. El modelo tecnocrático y la crisis de legitimidad. 2. La mutación de la naturaleza integración europea: de la economía a la política. 3. El debate constitucional y el Tratado de Lisboa. - IV. Algunos retos pendientes de la integración europea. 1. La incorporación de los actores no estatales: regiones, naciones sin Estado. 2. Las Naciones sin Estado. 3. La Europa social y el neoliberalismo. 4. El futuro de Europa, ¿diplomacia o democracia? Hacia una nueva convención.
\end{abstract}

Resumen: El presente artículo, a modo de balance provisional, señala algunos de los principales hitos del proceso de integración europea: la paz entre los Estados europeos - una verdadera paz estructural - , la Unión política, el tratado constitucional. Pero tampoco pueden olvidarse las insuficiencias con el déficit democrático $y$, en particular, tres retos que debe afrontar: el encaje de las regiones y naciones sin Estado, el debate sobre el modelo social en Europa y la forma de continuar el proceso de integración, superando el alejamiento de los ciudadanos y fomentando una participación activa de los mismos. Para ello, se concluye, es necesaria una nueva Convención, única forma de volver a ilusionar a los ciudadanos con un proyecto europeo atractivo.

Palabras clave: Unión Europea, integración, convención, Europa social, regiones.

Abstract: This article evaluates the main outcomes and shortcomings of the European integration process since Maastricht. Some of the main achievements to be pointed out are the old goal of achieving peace in the continent - a true structural peace-, the political Union, and the constitutional treaty. But there have been important shortcomings as well, such as some sort of democratic deficit, and other challenges like the accommodation of regions and nations without state, the debate on the European social model, or the way of reforming the Union in the future. It is said that a new Convention, with an improved participation and representation, is much needed in order to reattach citizens to the European enterprise.

Keywords: European Union, integration, convention, Social Europe, regions.

* Recibido el 20 de enero, aceptado el 3 de febrero. 


\section{Introducción}

El presente artículo, a modo de balance provisional, señala algunos de los principales hitos del proceso de integración europea. En primer lugar, se aborda el que probablemente constituya el mayor logro de la integración, el final de las innumerables guerras entre las potencias: lo que podríamos denominar la paz estructural europea. Bien entendido que la ausencia de guerras no significa que no haya habido otros conflictos armados dentro del suelo europeo ni que hayan desaparecido todas las violencias, como la estructural o la cultural (Galtung).

Otro hito de primera magnitud fue el salto hacia lo político que se produjo con la creación de la Unión Europea. Si bien el proceso de construcción europea había funcionado razonablemente bien, su método, funcionalista y tecnocrático, comenzó a ser cada vez más cuestionado y perder legitimidad a medida que las Comunidades Europeas se transformaban (mutaban) en una Unión política. Puede decirse que cuando se completó el Mercado Interior y se inició el despliegue de la Unión Económica y Monetaria, es cuando más comenzó a cuestionarse el modelo de integración, uno de cuyos hitos fue la moneda única. El euro constituye no sólo un poderoso instrumento sino un verdadero símbolo de la Unión Europea.

Resulta sorprendente que exactamente a la vez que se acordaba el Tratado de la Unión Europea que sería firmado posteriormente en Maastricht, la Unión Soviética (URSS) colapsaba y se desintegraba. En diciembre de 1991 una gigantesca federación se desvanecía en el mismo instante en que otra gran Unión política se alzaba más al oeste. Más allá del movimiento tectónico que esto supuso para la geopolítica mundial, el colapso de la URSS hizo posible el derribo del Muro de Berlín. El muro de la vergüenza, que había separado familias y que simbolizaba la división de Europa, una vez derribado por los propios ciudadanos, permitió la reunificación de Alemania y de Europa, convirtiéndose ahora en símbolo de unión. Las adhesiones en masa de 2004 (con su corolario en 2007 y 2013) amplió el número de miembros de la Unión hasta los 28 Estados.

Ese año, 2004, será recordado probablemente como uno de los grandes hitos de la historia de la integración, pues confluyen dos elementos de primer orden: por un lado, la Unión dio la bienvenida de forma solemne a los nuevos países hermanos del centro y este de Europa; por otro lado, se adoptaba formalmente el texto constitucional que había redactado la Convención, y en cuyos debates habían participado los nuevos miembros.

Después de este clímax, Europa entró en una fase de decepción y desconcierto. Los problemas en la ratificación del nuevo tratado, que ya habían sido avanzados por resultados negativos en tratados anteriores, esta vez resultaron insalvables. Se inició una fase de crisis de modelo, cuya salida de 
compromiso fue el Tratado de Lisboa. Si bien es cierto que no resiste la comparación con un tratado constitucional, tampoco puede ser infravalorado, pues supone un avance significativo en multitud de ámbitos cuyo alcance apenas somos capaces de vislumbrar en la actualidad.

Este breve repaso de algunos de los principales hitos en el camino de la integración europea nos sitúa en un escenario complicado pero apasionante. La Unión Europea seguramente constituye el mayor experimento político pacífico de la Historia, mostrando excepcionales logros a la vez que afronta retos igualmente extraordinarios.

Por ello, la segunda parte del artículo trata de identificar algunos de estos retos que afronta hoy la Unión Europea. En primer lugar, el encaje y acomodación de los actores no estatales, con particular atención a las regiones y naciones sin Estado, tema central de la agenda europea en un año en el que se producirá - al menos - el referéndum sobre la independencia de Escocia.

En segundo lugar, el cuestionamiento del modelo social europeo ante los embates neoliberales de la últimas tres décadas, que ha causado una considerable disminución en el nivel de protección social en toda Europa. No cabe duda de que este retroceso social, en el contexto de la crisis actual, ha alarmado a los ciudadanos europeos y es una de las principales razones del descrédito general de la política y de la deslegitimación de las instituciones, también las europeas.

En tercer lugar, el futuro de Europa - su futuro político e institucional-, lleva ya un tiempo en la agenda. Los ciudadanos europeos, a pesar de apenas contar con medios de alcance continental, llevan años debatiendo sobre la Europa que quieren. Desde el fracaso diplomático de Niza hasta el rechazo del texto aprobado por la convención, Europa no ha dejado de modificar los tratados, pero sin aclarar del todo el futuro. Hoy se habla de unión bancaria y fiscal, de eurobonos, y hasta de federación, a la vez que otros hablan de simple mercado e incluso de abandonar la Unión (Reino Unido).

No sólo está en cuestión la dirección de la reforma futura, sino la forma de realizarla. En este debate clave hay dos grandes metodologías, diplomacia y democracia, estando la primera ligada a las viejas Conferencias Intergubernamentales (CIG) y la segunda a las dos convenciones ya realizadas para elaborar la Carta de Derechos Fundamentales de la UE y la propuesta de Tratado Constitucional para la UE. Aquí se sostendrá que, por una cuestión de principios, pero también por puro pragmatismo dado el contexto actual, resulta imprescindible preparar el camino a una próxima gran Convención europea en la que se debatan de forma abierta, inclusiva, transparente y democrática los grandes retos de la Unión, y cuyos resultados puedan ser votados directamente por los ciudadanos antes de implementarse. Sólo así 
se podrán sortear ciertos resabios imperiales y la presión de los poderosos grupos de interés, e ilusionar a la ciudadanía europea con un proyecto político a la altura de las circunstancias. Es necesario que los ciudadanos europeos sientan que al fin gobiernan su futuro.

Cien años después del inicio de la Gran Guerra, sesenta años después de iniciarse el proceso de integración y veinte años después de Maastricht, es hora de mirar atrás para valorar lo conseguido, aprender de los errores y encarar con ilusión el futuro. Esto sólo es posible conseguirlo en una convención no monopolizada por los Estados, en la que ciudadanos, regiones, minorías nacionales, movimientos sociales y ONGs puedan participar libremente. Sabiendo que luego, además, deberán ratificar lo aprobado en un referéndum europeo celebrado a la vez en todo el territorio de la Unión, que marcaria un hito democrático, fundacional, en la historia de la integración.

\section{Integración europea y paz: la paz estructural}

Son suficientemente conocidos los numerosos proyectos que, mediante la integración del continente, pretendían terminar con las guerras europeas: William Penn, el abate Saint Pierre, Bentham, Kant, Saint Simon, Krause, Coudenhove-Kalergi, etc. El punto de inflexión se produce tras la Gran Guerra con la obra del conde Koudenhove-Kalergi, Paneuropa (1923), que tras afirmar la crisis o decadencia de Europa, planteamiento que no era original, elabora un diagnóstico y una consecuencia, ésta sí, novedosa: «la dolencia de Europa consistía en su división política en más de veinte Estados, generadora de anarquía internacional, con su secuela de continuas guerras». Por ello era necesario crear una federación europea, ya que «sin tal unión política permanente, los Estados europeos, además, se verían conducidos nuevamente a la guerra. Ahora bien, una nueva guerra asestaría a Europa el golpe mortal». ${ }^{1}$ Del mismo modo, Robert Schuman y Jean Monnet, con su contraparte alemán Konrad Adenauer, entre otros líderes, son considerados los padres fundadores de las Comunidades Europeas. ${ }^{2}$

Menos conocidos son los esfuerzos realizados por estos dos países durante el periodo de entreguerras, entre Aristide Briand y Gustav Stresemann. Briand fue primer ministro de Francia durante los duros años de la Gran Guerra y luego ministro de asuntos exteriores entre 1925 y 1932. Lo destacable es que, a pesar de su experiencia en la guerra, siempre consideró ne-

1 TRUYOL, A., La integración europea. Análisis histórico-jurídico con textos y documentos. Madrid, Tecnos, 1999, pp. 21-28.

2 ALDECOA, F., La integración europea. Análisis histórico-jurídico con textos y documentos. Vol. II: Génesis y desarrollo de la Unión Europea. Madrid, Tecnos, 2002. 
cesaria la reconciliación franco-alemana como pilar de cualquier acuerdo de paz más amplio y contrapeso a la hegemonía norteamericana. En base a estas ideas, Briand esbozó una propuesta de Unión Europea en 1929, que presentaría formalmente ante la Sociedad de Naciones y los gobiernos europeos. Una de las ideas centrales era convertir la cooperación económica francoalemana, y en particular su producción de acero conjunta, en una herramienta al servicio de la paz. En aquel momento, el Reino Unido observaba con curiosidad y cierta preocupación aquellos movimientos. Su primer ministro, Winston Churchill, afirmaría en una entrevista a un diario alemán que la actitud británica hacia la integración era de apoyo pero no de compromiso, ya que operaban en otros espacios de mayor significado material y emocional para ellos. ${ }^{3}$ Tras la crisis del Ruhr (1923-24) y la firma del Tratado de Locarno, Briand propuso formalmente a Alemania iniciar la cooperación industrial mutua y avanzar hacia unos Estados Unidos de Europa, abiertos a los 26 Estados europeos. La respuesta alemana fue constructiva. Sin embargo, la profunda crisis de 1929, que hizo insoportable el pago de las reparaciones de guerra y, sobre todo, las muertes de los interlocutores más comprometidos (Briand y Stresemann) envenenaron unas relaciones diplomáticas «sorprendentemente cordiales» y arruinaron la viabilidad del plan. ${ }^{4}$

Merece la pena recordar estos esfuerzos y diseños de la Europa del futuro esbozados en 1929-32 e injustamente olvidados, porque estos cimientos fueron tan sólidos como para resistir el impacto de Hitler y la Segunda Guerra Mundial.

A partir de la experiencia de cooperación entre los países aliados durante las dos guerras mundiales ${ }^{5}$, y bajo el liderazgo del gobierno francés (Robert Schuman, Jean Monnet), el 9 de mayo de 1950 Francia le propuso a Alemania y a todos los países europeos interesados, en fusionar sus producciones de carbón y acero en una Comunidad Europea bajo la supervisión y coordinación de una autoridad supranacional.

Esta propuesta constituye una de las mayores innovaciones políticas en mucho tiempo, pues en esencia significa el abandono del modelo del Estado moderno europeo, basado en la soberanía, para avanzar hacia otro modelo de Estado - que ha sido calificado como posmoderno - y que supone que las autoridades aumenten su capacidad reguladora y su poder al compartir sus antiguas soberanías y gestionarlas en común.

3 Berliner Börsen-Courier, 11 enero 1931.

4 FISCHER, C., «The failed European Union: Franco-German relations during the Great Depression of 1929-32», International History Review, Vol. 34, n. ${ }^{\circ} 4$, 2012, pp. 705-724.

5 FILIBI, I., «El modelo europeo de resolución de conflictos: la paz estructural», en BRITO, W. y PUEYO, J. (coords.), Conflitos armados, gestao pós-conflitual e reconstruçao. Santiago de Compostela, Scientia Iuridica, 2011, pp. 453-474. 
Para comprender el auténtico significado y alcance de este cambio es necesario recordar cómo surge el modelo anterior. El Estado moderno europeo surge en Wesfalia en 1648. Después de décadas de sanguinarias guerras de religión (Guerra de los Treinta Años), las potencias europeas, incapaces de eliminar al enemigo religioso (católico/protestante), acordaron reconocer el derecho que asistía a cada príncipe para imponer su religión en su propio territorio. Todos respetarían este principio de soberanía territorial exclusiva, que implicaba la prohibición de intervenir en el territorio ajeno, y que desde entonces ha sustentado el sistema internacional. En otras palabras, la soberanía fue la solución a las guerras de religión europeas.

Curiosamente, la misma soberanía que resolvió las guerras de religión, fue considerada la causa de las guerras contemporáneas europeas y que culminaron con las dos salvajes Guerras Mundiales. ${ }^{6}$ Diversos intelectuales, particularmente los federalistas globales o integrales en el periodo de entreguerras, luego las resistencias europeas, y finalmente los propios gobiernos europeos, aceptaron el diagnóstico de que mientras los gobiernos siguieran ejerciendo de forma absoluta su soberanía, la guerra sería inevitable. Más allá del horror que supone toda guerra en la época de la industrialización, la deshumanización y barbarie vistas en Auschwitz e Hiroshima dejaban claro que se había llegado al límite. De haber otra gran guerra, en un clima de creciente tensión entre el este y el oeste, volvería a producirse en Europa y con total seguridad sería la última.

Sólo en este contexto puede entenderse el nuevo diagnóstico - lo que se consideraba el problema alemán pasa a ser ahora un problema euro$\mathrm{peo}^{7}$ - y la arriesgada decisión de compartir soberanía entre los antes enemigos, para crear una Unión Europea. Una vez identificada con precisión la causa - la soberanía - y definido correctamente el problema, la solución aparece con claridad: la federación supranacional. ${ }^{8}$

En palabras de Jean Monnet, el inspirador de la propuesta francesa, era precisa «una acción profunda, real, inmediata, espectacular que dé una respuesta a las esperanzas de los pueblos europeos». ${ }^{9}$

La principal esperanza era la de lograr la paz. Weiler observa que, «tras la Segunda Guerra Mundial, la paz constituía el ideal más explícito y evocador a cuyo servicio se debían poner las políticas del futuro. En ningún

${ }^{6}$ FILIBI, I., La Unión política como marco de resolución de los conflictos etnonacionales europeos: un enfoque comparado. Leioa, Servicio Editorial de la UPV/EHU, 2007, p. 30.

7 MONNET, Memorias, op. cit.

${ }^{8}$ CHITI-BATELLI, A., Éducation fédéraliste et culture européenne. Nice, Presses d'Europe, 1992; pp. 11-2.

9 MATTERA, A., «De la deuxième guerre mondiale au "projet européen" de Jean Monnet», Revue du Droit de L'Union Européenne, núm. 1, 2002; p. 23. 
documento se recoge mejor esta situación que en la conocida Declaración Schumann de 9 de mayo de 1950». ${ }^{10}$ En ese texto, Robert Schuman, ministro francés de Asuntos Exteriores, hacía la histórica declaración que proponía la puesta en común de las soberanías en una organización supranacional que gestionase las producciones de carbón y acero de los países europeos. El propio lenguaje empleado en esta declaración muestra claramente que las motivaciones no se reducían a la dimensión económica, sino que incluían profundas consideraciones sobre la guerra y la paz. ${ }^{11}$ Una sola frase resume el sentido de la propuesta: «Europa no se hizo, y tuvimos la guerra». Por ello, sigue, «esta propuesta pondrá las primeras bases de una federación europea indispensable para el mantenimiento de la paz».

Se asume así, con todas sus consecuencias, que la soberanía es la auténtica raíz del conflicto y de la guerra; que es indispensable ponerla en común si se quiere mantener la paz. Tras el diagnóstico y la solución, se especifica el mecanismo concreto a utilizar:

El Gobierno francés propone llevar inmediatamente la acción sobre un punto limitado, pero decisivo.

(...) colocar el conjunto de la producción franco-alemana de carbón y acero bajo una alta autoridad común en una organización abierta a la participación de los demás países de Europa.

(...) primera etapa de la federación europea (...) (Subrayado nuestro).

La propuesta de una acción sobre un punto limitado pero decisivo, esto es, estratégico, hacia la federación europea, abre el camino al objetivo político prioritario: la paz. Pero ya no será una paz más firmada en un tratado que se incumplirá en cuanto convenga, sino un nuevo y revolucionario tipo de paz, una paz estructural. La Declaración dice:

La solidaridad de producción que de ello resulte pondrá de manifiesto que toda guerra entre Francia y Alemania se hace, no ya impensable, sino materialmente imposible. (Subrayado nuestro).

Estas son las dos dimensiones que incorporamos bajo el concepto «paz estructural»: que sea materialmente imposible e impensable la guerra entre los

10 WEILER, J. H. H., Europa, fin de siglo. Madrid, Centro de Estudios constitucionales, 1995; p. 172.

11 WISE, M., «War, peace and the European Community», en KLIOT, Nurit and WATERMAN, Stanley (eds.), The political geography of conflict and peace. London, Belhaven Press, 1991, p. 114. Sobre la conexión general entre la paz y el proceso de integración, Vid. BÓKA, E., «The European idea of a supranational union of peace», Society and Economy, Vol. 34, n. ${ }^{\circ}$ 3, 2012, pp. 387-397; GALTUNG, J., The European Community: A superpower in the making, 1973, pp. 58-9. 
países europeos federados. Se unen aquí tanto la dimensión material como la ideológica, esto es, conformando la paz estructuralmente, en un sentido fuerte.

La mejor prueba del éxito de este planteamiento es su resultado histórico. No ha vuelto a haber una guerra entre los países de las Comunidades Europeas, ahora Unión Europea. La única experiencia en este sentido fue la sucesión de conflictos en la descomposición de la antigua Yugoslavia, justo en la frontera externa de la Unión Europea. Más allá de la ausencia de guerras, en la actualidad nadie puede imaginarse un conflicto armado entre, por ejemplo, Alemania y Francia. Efectivamente, se trata de algo impensable e incluso aunque un gobierno se volviese loco y lo quisiese, es tal el grado de interdependencia entre las economías, las burocracias y las sociedades europeas, que tal intento sería materialmente imposible. Exactamente lo que la propuesta de Schuman pretendía lograr.

No obstante, terminar con las guerras entre los Estados de la Unión Europea, es decir, superar la violencia interestatal, no significa que se terminasen todos los conflictos armados dentro de Europa (IRA, ETA, etc.) ${ }^{12}$, ni que no sigan existiendo otras formas de violencia (estructural, cultural). ${ }^{13}$

Por otro lado, el método comunitario de resolución de conflictos, esta paz estructural, no se agota en los conflictos armados interestatales. Puede identificarse una lógica expansiva ${ }^{14}$ por la que la Unión Europea ha intervenido en la resolución de conflictos tanto fuera de sus fronteras (Oriente Medio, Guatemala, Chipre, etc. $)^{15}$, como incluso en conflictos internos como en Irlanda del Norte ${ }^{16}$ y a través de instrumentos como la cooperación transfronteriza. ${ }^{17}$

12 FILIBI, I., La Unión política como marco de resolución de los conflictos etnonacionales europeos: un enfoque comparado. Leioa, Servicio Editorial de la UPV/EHU, 2007.

13 BEHR, H., «EUrope - History, violence and "peripheries"», Review of European Studies, Vol. 4, n. ${ }^{\circ}$ 3, 2012, pp. 7-17.

${ }^{14}$ FILIBI, I., «Moldeando la paz estructural. Proceso de integración europeo y resolución de conflictos», Working Papers Munduan, n. ${ }^{\circ}$ 9, 2005; FILIBI, I. La Unión política..., op. cit.

15 STIVACHTIS, Y.A., PRICE, C. y HABEGGER, M., «The European Union as a peace actor», Review of European Studies, Vol. 5, n. ${ }^{\circ}$ 3, 2013, pp. 4-17; HAYWARD, K. y MURPHY, M.C., "The (soft) power of commitment: The EU and conflict resolution in Northern Ireland», Ethnopolitics, Vol. 11, n. ${ }^{\circ}$ 4, 2012, pp. 439-452; UNCETABARRENECHEA, J., «La doble crisis del proceso de integración europea y el futuro de la UE como agente activo en la resolución de conflictos», en BRITO, W. y PUEYO, J. (coords). Conflitos armados, gestao pós-conflitual e reconstruçao. Santiago de Compostela, Scientia Iuridica, 2011, pp. 399-415; DE CASTRO, J.L. (dir.), La contribución de la Unión Europea a un acuerdo de paz israelo-palestino: luces y sombras. Vitoria-Gasteiz, Eurobask, 2007.

16 FILIBI, I., «La UE y la resolución de conflictos internos: el caso de Irlanda del Norte», en VÁZQUEZ GÓMEZ, E.M. et al. (coords.), El arreglo pacífico de las controversias internacionales. XXIV Jornadas de la Asociación Española de Profesores de Derecho Internacional y Relaciones Internacionales (AEPDIRI). Valencia, Tirant lo Blanch, 2013, pp. 933-948.

17 McCALL, C., «European Union cross-border cooperation and conflict amelioration», Space and Polity, Vol. 17, n. ${ }^{\circ}$ 2, 2013, pp. 197-216. 


\section{Del modelo tecnocrático al debate político: la Unión Europea}

\section{El modelo tecnocrático y la crisis de legitimidad}

La integración europea se inició como un proceso elitista, liderado por la tecnocracia de la Comisión, en el que el consentimiento popular se daba por descontado. Incluso las instituciones que parecían dotar al proyecto europeo de más legitimidad democrática, como el Parlamento Europeo, en su origen se debían poco a un deseo genuino de lograr una Europa democrática en sentido pleno de representación y rendición de cuentas. ${ }^{18}$ En realidad,

las tácticas de Jean Monnet y sus seguidores estaban claramente diseñadas para reducir al mínimo la posibilidad de un inflamable debate público sobre el modelo. De esta forma, la negociación e intermediación que culminó en el compromiso supranacional sirvió no sólo para satisfacer sino para calmar a las principales fuerzas políticas. ${ }^{19}$

Así, el modelo de integración se basó en el trabajo de instituciones supranacionales en colaboración con los gobiernos de los Estados miembros $^{20}$, bajo el arbitraje y la garantía del Tribunal de Justicia. Esta política tecnocrática permitió ir avanzando en el proceso de integración y convertir en un asunto técnico cuestiones de gran calado político. ${ }^{21}$ Con todo, resultó aceptable entre seis países, con una agenda limitada y en el contexto del liderazgo norteamericano y la amenaza externa soviética. Sin estas condiciones, se ha desvanecido la posibilidad de mantener el consenso permisivo de las primeras décadas de la integración. ${ }^{22}$

${ }^{18}$ En realidad, una vez que el Consejo de Europa incluyó una asamblea parlamentaria, resultaba inconcebible que la primera Comunidad Europea no tuviese una. Pero ello no significaba que hubiese un genuino deseo de democratizar la organización ni de favorecer su rendición de cuentas, como demuestra el caso de la Unión Europea Occidental (UEO), refundada en 1954, y cuya asamblea parlamentaria resultó invisible por más de cuarenta años.

19 LINDBERG, L. y SCHEINGOLD, S., Europe's would-be polity. Englewood Cliffs, Prentice hall, 1970, p. 21.

${ }^{20}$ Sobre las duras batallas políticas acerca del sistema de representación negociadas por los padres fundadores, Vid.: RITTBERGER, B., «The historical origins of the EU's system of representation», Journal of European Public Policy, Vol. 16, n. ${ }^{\circ}$ 1, 2009, pp. 43-61.

${ }^{21}$ HARCOURT, A.J. y RADAELLI, C.M., «Limits to EU technocratic regulation?», European Journal of Political Research, Vol. 35, n. ${ }^{\circ}$ 1, 1999, pp. 107-122; FISCHER, R., «European governance still technocratic? New modes of governance for food safety regulation in the European Union», EIOP European Integration Online Papers, Vol. 12, n. ${ }^{\circ}$ 1, 2008.

22 WALLACE, W. y SMITH, J., «Democracy or technocracy? European integration and the problem of popular consent», en HAYWARD, J. (ed.), The crisis of representation in Europe. Abingdon, Frank Cass, 1995, p. 154. 
En ese contexto, tratando de aclarar la paradoja del denominado déficit democrático de la Unión Europea, formada por Estados democráticos, Joseph Weiler distinguió entre legitimidad formal o legal y legitimidad social, señalando que las instituciones comunitarias poseían la primera, pero carecían de la segunda. ${ }^{23}$ También se ha señalado que la UE adolece de un doble déficit democrático, tanto de democracia como de representación. ${ }^{24}$ En opinión de Ramón Torrent, ya en los años 80 se ven signos claros de que los ciudadanos estaban completamente alejados del proceso de integración, y señala que «el petit oui francés en el referéndum del Tratado de Maastricht habría debido servir de señal de alerta mucho más aún que el «no» danés. Más allá de los resultados electorales bastaba un mínimo de perspicacia y sensibilidad para comprobar un malestar creciente».25

A pesar de ello, solo tras la firma del Tratado de Maastricht se cuestionó abiertamente la legitimidad democrática de la integración europea ${ }^{26}$, en particular cuando la negativa a aceptar el tratado en el referéndum danés dejo claro que el acuerdo entre los doce gobiernos no garantizaba el apoyo popular: el consenso permisivo se había roto. ${ }^{27}$

No obstante, es justo reconocer que la Comisión Europea ya estaba preocupada por los aspectos de legitimación desde hacía mucho tiempo, antes de que se rompiese este consenso tácito. ${ }^{28}$ Entre 1973 y 1994, la Comisión Europea ha ido desarrollando diversas estrategias de legitimación que se han expresado en tres narrativas principales:

a) En primer lugar, la narrativa de una Europa funcionalista, probablemente la más influyente a lo largo de todo el proceso de integración, sobre todo entre 1973 y 1984, y que aún es muy relevante, como se

${ }^{23}$ WEILER, J.H.H., «After Maastricht: Community legitimacy in post-1992 Europe», en ADAMS, W.J. (ed.), Singular Europe. Michigan, University of Michigan, 1992.

${ }^{24}$ BELLAMY, R. y KRÖGER, S., «Representation deficits and surpluses in EU policymaking», Journal of European Integration, Vol. 35, n. ${ }^{\circ}$ 5, 2013, pp. 477-497.

25 TORRENT, R., «¿Cómo se engendró en los años 1980 la crisis del proceso de integración europea que ha estallado en los años 2000?», Cuadernos Europeos de Deusto, n. ${ }^{\circ}$ 37, 2007, p. 160; citado por PETITHOME, M., op. cit., p. 143.

${ }^{26}$ Dos argumentos justificaban esta posición, por un lado, que la integración constituía un proceso que iba progresando con cada avance hacia una democracia avanzada, y por otro lado, porque se trataba de un experimento institucional original, que no podía ser comparado con los sistemas políticos existentes (PETITHOMME, M., «La despolitización de la política europea y el dilema del déficit democrático», Cuadernos Europeos de Deusto, n. ${ }^{\circ} 39,2008$, pp. 137-167).

27 WALLACE, W. y SMITH, J., op. cit., p. 150.

${ }^{28}$ HOOGHE, L. y MARKS, G., «Postfunctionalist theory of European integration: From permissive consensus to constraining dissensus», British Journal of Political Science, Vol. 39, n. ${ }^{\circ} 1,2009$, pp. 1-23. 
puede observar al analizar el Libro Blanco sobre la Gobernanza Europea. Esta narrativa busca legitimar la actuación comunitaria y en particular la de la Comisión en base a la obtención de resultados objetivos y medibles que justifiquen la cesión de soberanía, se trataría de una estrategia basada en la eficacia.

b) En segundo lugar, la narrativa de la identidad europea, que obtuvo su preeminencia fundamentalmente entre 1985 y 1989 y que se sustentaba en la posibilidad de crear las estructuras sociales y políticas de una verdadera comunidad, con su propia identidad y sentimiento de pertenencia, expresado en símbolos comunes (bandera, himno, carnet de conducir europeo, sellos, pasaporte europeo), programas de intercambio ${ }^{29}$, cátedras sobre temas europeos, etc. En esta época se produjo un enorme esfuerzo en destacar la existencia de un pueblo europeo, una cultura europea y unos valores europeos.

c) En tercer lugar, la narrativa de una Europa democrática adquirió preeminencia entre 1990 y 1994, cuando se afirmaba que el apoyo político del proceso de integración sólo podría obtenerse si se mejoraba la relación entre los ciudadanos y las instituciones europeas. Las palabras claves aquí fueron ciudadanía, transparencia, subsidiariedad y comunicación.

A pesar de que las tres narrativas han tenido periodos en los que han poseído una cierta preeminencia, en la actualidad las tres se encuentran presentes, de una forma u otra, en los discursos y documentos oficiales de la Comisión y las otras instituciones comunitarias. ${ }^{30}$

En definitiva, los esfuerzos que se han realizado hasta la fecha para solucionar el «déficit democrático» de la Unión han fracasado, lo que parece indicar que «el problema del déficit democrático no refleja solamente un problema de comunicación política ineficiente, sino sobre todo, pone de manifiesto las tendencias a la despolitización de los asuntos europeos en el nivel nacional y de la toma de decisiones en el nivel europeo». ${ }^{31}$

${ }^{29}$ MUTLU, S., «Development of European consciousness in Erasmus students», Journal of Education Culture and Society, n. ${ }^{\circ} 2,2011$, pp. 87-102.

${ }^{30}$ BIEGON, D., «Specifying the arena of possibilities: post-structuralist narrative analysis and the European Commission's legitimation strategies», Journal of Common Market Studies, Vol. 51, n. ${ }^{\circ}$ 2, 2013, pp. 194-211. Otra fórmula usada habitualmente por las instituciones comunitarias, y en particular por la Comisión, dadas sus limitaciones en términos de legitimidad, consiste en inseminar soluciones en los sistemas políticos nacionales al fomentar la emulación de prácticas ya ensayadas en otros países, como códigos de buenas prácticas, etc. (RADAELLI, C.M., «Policy transfer in the European Union: Institutional isomorphism as a source of legitimacy», Governance, Vol. 13, n. ${ }^{\circ}$ 1, 2000, pp. 25-43).

31 PETITHOMME, M., op. cit., p. 142. 
Este es un asunto clave, y merece detenerse, siquiera brevemente, en algunos de los elementos que favorecen la despolitización de la UE. Al analizar y clasificar los partidos políticos de los Estados miembros respecto a la integración europea, se constata que su posición como partido de gobierno o de la periferia resulta más relevante que el eje izquierda/derecha. ${ }^{32}$ La consecuencia inmediata de esto es que las posturas más críticas sobre la integración están sistemáticamente ausentes del proceso de toma de decisiones europeo y ello hace que el votar a un partido de centro-izquierda o centro-derecha no provocará ningún cambio apreciable en la política europea. Además, el relativo consenso entre las élites políticas genera una cierta despolitización de la política europea. Por otro lado, la naturaleza institucional de la UE, con sus fuertes presiones para adoptar decisiones consensuales, es otro factor que ayuda a despolitizar la política europea. El último ejemplo de esto es la propuesta de una constitución sin proceso de constitucionalización propiamente dicho, una muestra más de «la tendencia a la toma de decisiones que no han sido el resultado de una competición política entre distintas alternativas ideológicas». Otro ejemplo destacado se observa en el funcionamiento del Banco Central Europeo, un órgano compuesto por miembros nominados (no electos), y cuyas políticas no pueden ser alteradas por los ciudadanos ni por sus representantes electos gracias a su «independencia», garantizada por los tratados. Finalmente, la Comisión Europea tiende a despolitizar las cuestiones mediante el empleo sistemático de expertos, favorecido por la enorme complejidad del derecho comunitario. ${ }^{33}$

Por otro lado, a pesar de que la ampliación progresiva del procedimiento de codecisión ha reforzado el poder del Parlamento Europeo, no se ha resuelto el problema de la representación y del control político efectivo de las decisiones europeas. Esto también merece un breve comentario.

Si se observa la dinámica política histórica de la integración, desde 1957 las sucesivas reformas de los tratados han tendido a conferir más poder al Parlamento Europeo y a la Comisión. Sin embargo, los últimos tratados parecen haber reducido el poder de la Comisión ${ }^{34}$ y, pese a la generalización del procedimiento de codecisión, que en teoría sitúan al Consejo y al Parlamento en términos de igualdad, el Parlamento Europeo aún no ha alcanzado una auténtica paridad con el Consejo, que mantiene ciertas venta-

32 HOOGHE, L., MARKS, G. y WILSON, C.J., «Does left/right structure party positions on European integration?», en MARKS, G. y STEENBERGEN, M.R. (eds.), European integration and political conflict. Cambridge, Cambridge University Press, 2004, pp. 235-260.

33 PETITHOME, M., op. cit., pp. 148-9, 160-2 y 165.

34 DINAN, D., «Governance and institutions: Implementing the Lisbon Treaty in the shadow of the Euro crisis», Journal of Common Market Studies, 49 (Annual Review), 2011, pp. 103-121. 
jas en el proceso negociador. ${ }^{35} \mathrm{El}$ argumento del declive de la Comisión es polémico. Algunos autores afirman que, aunque la Comisión no ha perdido formalmente competencias en aspectos significativos, sus propios oficiales consideran que la institución ha ido perdiendo capacidad de influencia y poder político. ${ }^{36}$ Sin embargo, cuando se pregunta a los oficiales de la Secretaría y a los grupos políticos del Parlamento Europeo, consideran que la Comisión es el actor institucional más influyente, por encima del Consejo, y que ello motiva que los lobbies traten de influir en la Comisión más que en cualquiera otra institución europea. ${ }^{37}$ Un estudio reciente demuestra cómo la Comisión Europea es capaz de implementar las normas comunitarias incluso en aquellas áreas en las que los Estados desean evitar la transferencia de poderes reguladores al ámbito comunitario, como es el caso de las reglas de competencia en los servicios financieros. ${ }^{38}$

Esta capacidad política de la Comisión - esto es, su actividad relativamente autónoma de los gobiernos nacionales - , se deriva de su diseño institucional formal, basado en dos principios: el más importante, que la afiliación principal de sus decisores y líderes políticos sea la propia organización (y no sus Estados respectivos); y el segundo, un principio no territorial de especialización que apuntale la orientación no nacional de sus miembros. Puede decirse que la orientación nacional, en el caso del personal de la Comisión, no juega ningún papel significativo. Esta influencia es más ambigua en el caso de los comisarios/as, sin embargo, si se compara el comportamiento de los cargos ejecutivos de otra organización internacional como el Consejo de Europa, la diferencia es extraordinaria. En el caso del Consejo de Europa el poder de los gobiernos es decisivo, cosa que no ocurre en la Comisión Europea. Es por esto que la literatura especializada opina que cuanto mayor sea el poder del Parlamento en la elección de los comisarios/as, mayor autonomía tendrán éstos/as respecto a sus gobiernos nacionales. ${ }^{39}$

35 COSTELlO, R. y THOMSON, R., «The distribution of power among EU institutions: Who wins under codecisión and why?», Journal of European Public Policy, Vol. 20, n. ${ }^{\circ} 7$, 2013, pp. 1025-1039.

36 KASSIM, H., PETERSON, J., BAUER, M.W., CONNOLlY, S.J., DEHOUSSE, R., HOOGHE, L. y THOMPSON, A., The European Commission of the twenty-first century. Oxford, Oxford University Press, 2012.

37 EGEBERG, M., GORNITZKA, A., TRONDAL, J y JOHANNESSEN, M., «Parliament staff: unpacking the behavior of officials in the European Parliament», Journal of European Public Policy, 20, 2013.

38 SEIKEL, D., «How the European Commission enforces supranational law: The conflict about the liberalization of public banks in Germany», Politische Vierteljahresschrift, Vol. 54, n. ${ }^{\circ} 2,2013$, pp. 292-316.

39 EGEBERG, M., «Experiments in supranational institution building. The European Commission as a laboratory», ARENA Working Paper, n. ${ }^{\circ}$ 4, 2012. 


\section{La mutación de la naturaleza integración europea: de la economía a la política}

Tras una fase inicial en la que las Comunidades Europeas lograron apreciables éxitos, con la crisis energética y económica de 1973 la integración europea entró en una fase de estancamiento y cierta apatía. En esos años, la sensación de crisis intensificó los movimientos y actividades a favor de profundizar la integración. De entre la multitud de hechos, hay uno que será estratégico, no tanto por sus resultados inmediatos sino por su capacidad de introducir una nueva dinámica en la política comunitaria: la elección por sufragio directo del Parlamento Europeo en 1979. Al final de su primer mandato, el 14 de febrero de 1984, la cámara europea, ejerciendo su recién obtenida legitimidad democrática, aprobó el Proyecto de Tratado de Unión Europea. Se trataba de un nuevo esquema que gozó de una gran influencia y que inspiraría a partir de ese momento el debate político sobre el futuro de la integración.

El impacto de este nuevo actor sería de tal calibre que se ha llegado a considerar que impulsó una auténtica mutación en la naturaleza de la integración europea, hasta entonces sustentada en las dimensiones económica y técnica y que ahora pasaría a centrarse en los aspectos políticos. Los elementos fundamentales de la propuesta del Parlamento se irán concretando, a lo largo de fases sucesivas, en el Acta única Europea (1986) - que marcará como objetivo la Unión Europea - y los tratados de Maastricht (1992) - que creará la Unión Europea - y Amsterdam (1997) - que ya preveía su propia reforma en cinco años. ${ }^{40}$ Puede verse la velocidad de la integración, la rapidez e intensidad de los avances, en un contexto de cambios no menos acelerados (colapso de la Unión Soviética y fin de la Guerra Fría, creación de nuevos Estados que solicitan su ingreso en la Unión Europea).

La siguiente Conferencia Intergubernamental, celebrada en Niza en el año 2000, fue frustrante, ya que fue imposible lograr ningún acuerdo de fondo sobre los principales objetivos y retos de la Unión. Este fracaso quedó aún más en evidencia al ser comparado con el sorprendente éxito de la Convención que había redactado la Carta de Derechos Fundamentales de la Unión Europea ese mismo año. Estos dos acontecimientos, prácticamente simultáneos, «pusieron de manifiesto el agotamiento del método in-

40 ALDECOA, F., «La Unión Europea. La convergencia de los Estados nacionales», en MORÁN, G.M. (coord.), Nacionalismo en Europa, nacionalismo en Galicia: la religión como elemento impulsor de la ideología nacionalista. A Coruña, Universidade da Coruña, 1998, pp. 150-151. En contra de esta opinión, ha habido observadores que han señalado que la transición de una Europa de los gobiernos a otra basada en los ciudadanos se produce más con la firma y ratificación del Tratado de Maastricht, en 1992-1993 que con las primeras elecciones directas al Parlamento Europeo en 1979 (WALLACE, W. y SMITH, J., op. cit., p. 151). 
tergubernamental de negociación diplomática en manos de los gobiernos de los Estados. Se imponía así la necesidad de buscar una alternativa a la ineficacia de un método que hacía que las reformas se revisaran prácticamente antes de ver los efectos de su entrada en vigor». ${ }^{41}$

\section{El debate constitucional y el Tratado de Lisboa}

Fue un discurso del entonces ministro alemán de asuntos exteriores, Joschka Fischer, el que abrió el debate sobre el futuro y finalidad de la Unión Europea cuando propuso abiertamente elaborar un «tratado constitucional». Unas semanas más tarde, el 27 de junio de 2000, el presidente francés, Jacques Chirac, le respondía en el mismo Bundestag sugiriendo la apertura de un proceso formal de reflexión y señalando una lista concreta de temas sobre los cuales habría que discutir. Esta propuesta se convertiría en una Declaración anexa al Tratado de Niza y establecía las cuestiones mínimas que deberían debatirse en la nueva reforma, prevista para 2004: la distribución de competencias entre la UE y los Estados, el estatuto de la Carta de Derechos Fundamentales de la UE, la simplificación de los tratados para hacerlos comprensibles para los ciudadanos y el papel de los parlamentos nacionales dentro de la arquitectura institucional de la Unión.

El famoso discurso de Fischer sacudió el panorama político europeo y la necesidad de una reforma ambiciosa fue ganando peso entre los gobiernos y en toda Europa. El nuevo y ambicioso debate se concretó en la Declaración de Laeken (15 de diciembre de 2001), documento de reflexión que fija la composición y el mandato de la Convención Europea encargada de preparar la reforma. Este documento, por un lado, adopta una nueva filosofía, expresada en un nuevo lenguaje, y por otro lado, abre la segunda etapa de la reforma prevista en el Tratado de Niza para 2004. Es necesario recalcar que la propia Declaración constata que se ha producido un cambio en la naturaleza de la integración. En su origen, las primeras comunidades sectoriales eran de naturaleza fundamentalmente económica y técnica; ahora, fruto de esta mutación, la naturaleza de la integración pasa a ser predominantemente política. Ello obligaba a que el método comunitario que permitió avanzar en las primeras fases de la integración debería ser sustituido por otro mejor adaptado a las condiciones actuales. ${ }^{42}$

Dejando de lado el funcionamiento de la Convención y el proceso de elaboración del texto constitucional, que serán abordados más adelante, en

41 ALDECOA, F., «Comentarios al Tratado por el que se establece una Constitución para Europa ¿Qué es? ¿Un Tratado o una Constitución?», en Tratado por el que se establece una Constitución para Europa. Madrid, Biblioteca Nueva / Real Instituto Elcano, 2004, p. 26.

42 ALDECOA, F., «Comentarios al tratado...», op. cit., p. 29. 
aquel momento un mensaje fue calando en diversos sectores de la sociedad europea: «Europa necesita una constitución». El título y las razones que esgrimía Habermas en su conocido artículo siguen vigentes. ${ }^{43}$

Es suficientemente conocida la accidentada historia del proceso de ratificación, con los resultados negativos en varios referéndums, el periodo de reflexión sobre las causas del rechazo de los ciudadanos a aquel proyecto europeo, ${ }^{44}$ y el no menos complejo proceso de aprobación del Tratado de Lisboa, un auténtico rescate de todo lo salvable del tratado constitucional. Para terminar con este breve repaso de los hitos de la integración hay que resaltar que el Tratado Constitucional, elaborado por la Convención Europea y acordado por los gobiernos, constituyó la materialización de la propuesta aprobada exactamente veinte años antes por el primer Parlamento Europeo elegido democráticamente.

\section{Algunos retos pendientes de la integración europea}

Tal y como se ha visto, a medida que el proceso de integración europeo alcanzaba cotas constitucionales, el debate sobre los objetivos fundamentales de la Unión ha entrado en la discusión pública. Un sector de la opinión pública se opone al proyecto europeo, aunque es cierto que dentro del denominado euroescepticismo se encuentran posiciones muy distintas. Así, por un lado, no todas las voces contrarias a la UE son extremistas o populistas, del mismo modo que criticar la Unión Europea existente no significa ser euroescéptico. ${ }^{45}$ Por otro lado, a pesar de la importancia que tienen las posiciones más críticas en algunos países - destacando los casos de Hungría y Grecia - y de que en su conjunto seguirán siendo una fuerza política a tener en cuenta en la UE, no parece que en el futuro cercano puedan llegar a cuestionar la idea de integración, si bien el debate seguirá siendo relevante. ${ }^{46}$ En definitiva, dentro del amplio espectro de cuestiones debatidas, se han seleccionado tres que, en nuestra opinión y sin despreciar otros asuntos importantes, marcarán el debate en el futuro inmediato de la Unión Europea.

${ }^{43}$ HABERMAS, J., «Why Europe needs a Constitution», New Left Review, 11, 2001, pp. 5-26. Ver también: CANCELA, C., El procesode constitucionalización de la Unión Europea: De Roma a Niza. Santiago de Compostela, Universidade de Santiago de Compostela, 2001.

${ }^{44}$ FORNER MUÑOZ, S., «Proyecto europeo y opinión pública: las raíces de un creciente desencuentro», Historia y Política, Vol. 21, enero, 2009, pp. 95-115.

45 KANIOK, P., «Eurosceptics - enemies or a necessary part of European integration?», Romanian Journal of Political Science, Vol. 12, n. ${ }^{\circ}$ 2, 2012, pp. 29-52.

${ }^{46}$ HARTLEB, F., «European Project in danger? Understanding precisely the phenomena "euroscepticism, populism and extremism" in times of crisis», Review of European Studies, Vol. 4, n. ${ }^{\circ}$ 5, 2012, pp.45-63. 


\section{La incorporación de los actores no estatales: regiones, naciones sin Estado}

La literatura sobre la regionalización y el regionalismo europeo es inmensa y bien conocida. ${ }^{47}$ Las regiones, con su propia identidad y particularidades, forman parte de la historia y del alma europea. Europa no se entiende sin sus regiones. Por eso, cuando se habla de la diversidad europea, entre otras cuestiones, es preciso atender a la diversidad regional. ${ }^{48}$

No obstante, si bien puede identificarse una tendencia general hacia el renovado papel de las regiones en Europa desde los años 70 u 80 - en el marco del nuevo regionalismo y la redefinición de escalas ${ }^{49}$-, es cierto que ni todas las regiones son iguales ni todos los Estados presentan la misma casuística. ${ }^{50}$ Aquí radica una parte importante de la cuestión regional europea.

Más allá de su viejo interés por Europa, las regiones plantean de forma seria la necesidad de su participación en el entramado de poder comunitario con la creación de la Unión Europea. Fueron principalmente las regiones alemanas las que, gracias al sistema constitucional de Alemania, lograron incluir en la agenda de la CIG la cuestión regional. Después de una dura negociación, que incluyó la posición absolutamente contraria de algunos Estados descentralizados (España), finalmente el Tratado de Maastricht incluyó el reconocimiento formal de las regiones y la creación del Comité de las Regiones. Este hecho propagó la idea de una Europa de las regiones, e incluso algunos hablaron de una eventual Europa de los pueblos.

A pesar de este clima de optimismo por las oportunidades que parecían abrirse - como la propuesta lanzada por Alain Lammassoure de asociar ciertas regiones directamente con la UE-, pronto comenzaron a observarse los resultados reales y tangibles. Sin menospreciar algunos avances interesantes, ampliamente recogidos por la literatura, más de dos décadas después puede afirmarse que la participación regional en los asuntos comunitarios es, cuando menos, insuficiente. En particular, el Comité de las Regiones no es demasiado influyente ${ }^{51}$

${ }^{47}$ El libro seminal que abrió el debate fue: KEATING, M. y JONES, B. (eds.), Regions in the European Community. Oxford, Oxford University Press, 1985.

48 ROJO SALGADO, A., «La progresiva regionalización de la Unión Europea», Revista de Estudios Políticos, n. ${ }^{\circ}$ 104, 1999, pp. 181-211.

49 BRENNER, N., New state spaces, urban governance and the rescaling of statehood. Oxford, Oxford University Press, 2005; FERRERO, M. y FILIBI, M., «Globalización, espacio, ciudadanía. Notas preliminares para una filosofía política de la sociedad mundial», $R e$ vista de Investigaciones Políticas y Sociológicas (RIPS), Santiago de Compostela, Vol. 3, n. ${ }^{\circ} 1,2004$, pp. 7-24.

${ }^{50}$ ROJO SALGADO, A., «La experiencia del Estado regional en Europa: un referente para el caso español», Revista de Estudios Políticos, n. ${ }^{\circ}$ 127, 2005, pp. 233-273.

${ }^{51}$ HONNIGE, C. y PANKE, D., «The Committee of the Regions and the European Economic and Social Committee: How influential are consultative committees in the European Union?», Journal of Common Market Studies, Vol. 51, n. ${ }^{\circ}$ 3, 2013, pp. 452-471. 
y ello ha generado una profunda insatisfacción entre aquellas regiones con capacidad política y financiera que desean participar y defender activamente sus competencias en la UE.

Las insuficiencias del encaje regional contrastan con la pujanza de su actividad. Es un hecho que tanto el número de regiones como de sus poderes han aumentado en la Unión Europea. En la actualidad, las autoridades subestatales presentan una intensa actividad en sus relaciones con Bruselas y entre sí mediante multitud de organizaciones y redes. ${ }^{52}$ Estas regiones pueden defender sus intereses en los asuntos europeos bien a través de los mecanismos facilitados por el Estado - aunque sea de forma conflictiva - , bien mediante otras formas de participación ajenas al Estado: la denominada paradiplomacia. A su vez, esta paradiplomacia subestatal puede cooperar con la diplomacia estatal o bien tratar de sortear o puentear al Estado. ${ }^{53}$

Se ha señalado que la actividad paradiplomática resulta cada vez más similar a la diplomacia estatal, hasta el punto de que vendrían a ser casos comparables dentro de un fenómeno general. ${ }^{54} \mathrm{Si}$ bien esto puede ser discutido, dado que sólo sería completamente cierto en los casos de las regiones con poderes legislativos, la evidencia confirma que cuando los representantes subestatales son tratados formalmente de un modo similar a los representantes estatales se reduce notablemente la conflictividad en la defensa de los intereses. Esto se ha demostrado claramente en los casos de las autoridades subestatales británicas y belgas, pero también se aprecia la misma tendencia en los casos de las entidades subestatales austriacas, alemanas, italianas y españolas, así como en las islas Aland, Azores y Madeira. ${ }^{55}$ En el mismo sentido, se ha demostrado que el fortalecimiento y empoderamiento de las regiones mediante procesos de descentralización política aumenta la cooperación, antes que el conflicto, en Bruselas. ${ }^{56}$

52 DONAS, T. y BEYERS, J., «How regions assemble in Brussels: the organizational form of territorial representation in the European Union», Publius, Vol. 43, n. ${ }^{\circ} 3,2013$, pp. 527-550; THOUEZ, J.-P., «La region et l'intégration européenne», Canadian Geographer, Vol. 43, n. ${ }^{\circ} 3,1999$, pp. 304-315.

53 TATHAM, M., «"With or without you"? Revisiting territorial state-bypassing in EU interest representation», Journal of European Public Policy, Vol. 17, n. ${ }^{\circ}$ 1, 2010, pp. 76-99.

${ }^{54}$ CRIEKEMANS, D., «Regional sub-state diplomacy from a comparative perspective: Quebec, Scotland, Bavaria, Catalonia, Wallonia and Flanders», Hague Journal of Diplomacy, Vol. 5, n. ${ }^{\circ}$ 1-2, 2010, pp. 37-64; CRIEKEMANS, D. y DURAN, M., «Small state diplomacy compared to sub-state diplomacy: More of the same or different?», en STEINMETZ, R. y WIVEL, A. (eds.), Small states in Europe: Challenges and opportunities. Farnham, Ashgate, 2010, pp. 31-46.

55 TATHAM, M., «Paradiplomats against the state: Explaining conflict in state and substate interest representation in Brussels», Comparative Political Studies, Vol. 46, n. ${ }^{\circ}$ 1, 2013, pp. 63-94.

56 JEFFERY, C., «A regional rescue of the nation-state: Changing regional perspectives on Europe», Europa Institute Mitchell Working Paper Series, 5, 2007, pp. 1-16. 
En definitiva, las regiones europeas, dentro de una tendencia mundial ${ }^{57}$, son actores cada vez más activos que desafían los modelos estatales tradicionales de conducir las relaciones internacionales y exigen nuevos modos de acomodación. ${ }^{58}$

Sin embargo, las situaciones son muy diversas. ${ }^{59}$ Mientras se han producido algunos desarrollos significativos en Europa occidental, ${ }^{60}$ con todas sus insuficiencias, en los países de la Europa central y oriental, a pesar de su enorme riqueza y pluralidad étnica y nacional, sus Estados se encuentran entre los más centralizados de la UE. Todos los intentos de establecer modelos de federalismo (simétricos) ${ }^{61}$ o de autonomía (asimétricos) han fracasado hasta la fecha. Ello a pesar de que la descentralización era una exigencia de la condicionalidad impuesta por la UE en el periodo previo a la adhesión de estos países, de cara a recibir y gestionar los fondos regionales, etc. Los partidos de las etnias mayoritarias se oponen argumentando que temen que sea solo la primera fase en un proceso hacia la secesión o redefinición de las fronteras. ${ }^{62}$

57 CORnago, N., Plural diplomacies: Normative predicaments and functional imperatives. Martinus Nijhoff, 2013; CORNAGO, N., «Diplomacy within states? State fragmentation, agonistic respect, and diplomatic culture», ECPR Antwerp Joint research Sessions, 2012; CORNAGO, N., «On the normalization of sub-state diplomacy», en CRIEKEMANS, D. (ed.), Regional sub-state diplomacy today. Martinus Nijhoff, 2010, pp. 11-36; KEATING, M., «Regions and international affairs: Motives, opportunities and strategies», Regional and Federal Studies, Vol. 9, n. ${ }^{\circ}$ 1, 1999, pp. 1-16.

58 CRIEKEMANS, D., «Regional sub-state diplomacy from a comparative perspective: Quebec, Scotland, Bavaria, Catalonia, Wallonia and Flanders», en CRIEKEMANS, D. (ed.), Regional sub-state diplomacy today. Martinus Nijhoff, 2010, pp. 37-64 (sobre la situación europea, ver también el capítulo de Van den Brande, pp. 199-210); PAQUIN, S., «Paradiplomatie identitaire et diplomatie en Belgique fédérale: Le cas de la Flandre», Canadian Journal of Political Science, Vol. 36, n. ${ }^{\circ}$ 3, 2003, pp. 621-642; DURAN, M., «French regions as diplomatic actors: The case of Provence-Alpes-Cte dAzur», French Politics, Vol. 9, n. ${ }^{\circ} 4,2011$, pp. 339-363.

59 NESHKOVA, M.I., «Salience and complexity in supranational policymaking: The case of subnational interests», Governance - An international Journal of policy Administration and Institutions, Vol. 27, n. ${ }^{\circ}$ 1, 2014, pp. 9-36.

${ }^{60}$ No pueden olvidarse los desarrollos legales y políticos de la cooperación transfronteriza. Ver: ROJO SALGADO, A., «Las consecuencias de la cooperación transfronteriza: ¿Vamos hacia la refundación de Europa?», Revista de Estudios Políticos, n. ${ }^{\circ}$ 152, 2011, pp. 49-74; MEDEIROS, E., «Euro-Meso-Macro: The new regions in Iberian and European space», Regional Studies, Vol. 47, n. ${ }^{\circ} 8,2013$, pp. 1249-1266.

${ }^{61}$ No obstante esta distinción, Michael Keating ha señalado con claridad que la cuestión de la asimetría es más una disquisición teórica que un verdadero problema práctico, dado que la uniformidad predicada por los jacobinos no ha existido nunca fuera de su imaginación y que las condiciones ideales para un federalismo perfectamente simétrico son casi irrealizables (KEATING, M., «What's wrong with assymetrical government?», Regional \& Federal Studies, Vol. 8, n. ${ }^{\circ} 1,1998$, p. 213).

${ }^{62}$ BOCHSLER, D. y SZÖCSIK, E., «The forbidden fruit of federalism: Evidence from Romania and Slovakia», West European Politics, Vol. 36, n. ${ }^{\circ}$ 2, 2013, pp. 426-446. 
En el caso concreto español, el debate académico es largo y muy fructífero, iniciándose con el pionero estudio de Gurutz Jáuregui, ${ }^{63}$ pasando por las innovadoras propuestas de Francisco Aldecoa, ${ }^{64}$ y completándose con los múltiples análisis de casos concretos de comunidades autónomas. ${ }^{65}$

Si bien es cierto que se han producido hitos como la Sentencia del Tribunal Constitucional STC 165/1994, de 26 de mayo, que redefinió la propia noción de relaciones internacionales, la cuestión dista mucho de estar resuelta. Puede decirse que la participación de las Comunidades Autónomas en los asuntos europeos, a pesar de algunos avances como la incipiente participación en algunas formaciones del Consejo de la UE, es más formal que sustantiva. ${ }^{66}$

A la luz de lo señalado, puede concluirse con Michael Keating - en un número especial de la revista Regional \& Federal Studies de 1998 que hacía balance de la Europa de las Regiones, veinticinco años después- que si bien esta noción ha caído en desuso tanto por los académicos como por los políticos, ello no significa que la política territorial haya perdido un ápice de importancia, augurando su permanencia en la agenda comunitaria por mucho tiempo. ${ }^{67}$

\section{Las naciones sin Estado}

Dentro de la amplia variedad de casos que presenta el fenómeno regional, hay una variante particular que presenta características tan distintas que, en puridad, debería ser considerada como una problemática distinta.

63 JÁUREGUI, G., Comunidades Autónomas y Relaciones Internacionales. Oñate, IVAP/ HAEE, 1989.

${ }^{64}$ ALDECOA, F., «Hacia la diplomacia plurinacional en el contexto de la profundización y ampliación de la Unión Europea (1985-2005)», en KEATING, M. y ALDECOA, F. (coord.), Paradiplomacia: las relaciones internacionales de las regiones. Madrid, Marcial Pons, 2001, pp. 79-94.

65 Entre la amplia producción pueden destacarse, a modo de ejemplo: PUEYO, J. y PONTE, M.T., La actividad exterior y comunitaria de Galicia: La experiencia de otras comunidades autónomas. Santiago de Compostela, Fundación Alfredo Brañas, 1997; PONS RAFOLS, X. y SAGARRA, E., La acción exterior de la Generalitat en el nuevo Estatuto de Autonomía de Cataluña. Centre Estudis Internacionals, Universitat de Barcelona, 2006; DESRUES, T. y MORENO, J., «La acción exterior de la Junta de Andalucía en marruecos: el caso de la cooperación internacional para el desarrollo», Revista CIDOB d'Afers Internacionals, n. ${ }^{\circ}$ 79-80, 2007, pp. 247-264.

66 BELTRÁN, S., «Is there a real model in Spain for Autonomous Communities to participate in the Council of the European Union or is it only a mirage?», Journal of Contemporary European Studies, Vol. 20, n. ${ }^{\circ}$ 4, 2012, pp. 423-440. Para una visión matizada de esto, ver: NOFERINI, A., «The participation of Subnational governments in the Council of the EU: Some evidence from Spain», Regional \& Federal Studies, Vol. 22, n. ${ }^{\circ}$ 4, 2012, pp. 361-385.

${ }^{67}$ KEATING, M., «A quarter century of the Europe of the Regions», Regional and Federal Studies, Vol. 18, n. ${ }^{\circ}$ 5, 2008, pp. 629-635. 
Nos referimos a las comunidades nacionales que reclaman su reconocimiento como sujetos políticos plenos, con voluntad política diferenciada y que exigen una acomodación negociada en términos de igualdad. Algunas de estas realidades nacionales se han mostrado satisfechas con su encaje dentro de estructuras estatales descentralizadas, dotadas con grados variables de autogobierno, mientras otras han mostrado su malestar tanto social como políticamente, e incluso recurriendo a la violencia. No obstante estas importantes diferencias, lo común a todos los casos es que, por ser sujetos en sí mismos, cualquier acuerdo o situación será por definición provisional. Del mismo modo que los estudiosos del federalismo constatan que la mejor forma de entender las relaciones políticas entre entidades estatales complejas es comprenderlas en términos de proceso, aquí sucede lo mismo.

Cualquier sujeto político, sea o no un Estado, trata de adaptarse constantemente a las circunstancias que le rodean y le afectan: cambios geopolíticos mundiales, procesos de globalización y de integración, formas de legitimidad política dominante en cada momento, tendencias sociales y económicas, evolución en la percepción de los intereses y valores, relaciones con entidades políticas y sociales del entorno, etc.

No es el tema del artículo y por ello no profundizaremos en ello, pero sí que puede constatarse que los diversos movimientos nacionalistas europeos, al menos en la Europa occidental, fueron seducidos en su mayor parte por la promesa de una Europa unida, el sueño de la Unión política ${ }^{68} \mathrm{El}$ reconocimiento político explícito de las regiones del Tratado de Maastricht y la creación del Comité de las Regiones fueron interpretados como un primer paso en la dirección hacia la Europa de las regiones, e incluso hacia la más ambiciosa Europa de los Pueblos.

Muchos de estos movimientos nacionalistas adaptaron sus estrategias y discursos políticos al nuevo contexto de la Europa política. En su mayoría redefinieron sus nociones previas de soberanía e independencia para encajar en la nueva Europa ${ }^{69}$, y aceptaron con mayor facilidad que los nacionalismos estatales la idea central del método comunitario: la puesta en común de las soberanías. Unos años después de la creación de la Unión Europea, estas esperanzas fueron en gran medida frustradas. Al parecer, estas pequeñas naciones han vuelto a adaptarse al contexto de una Europa que sigue firmemente controlada por los Estados, y han retomado aspectos de sus estrategias anteriores a Maastricht, reclamando su derecho a constituir sus propios Estados. Pero, y esto es algo muy significativo, su idea de la soberanía ha cambiado, ahora no la comprenden ya como algo absoluto. Prácticamente

${ }^{68}$ FILIBI, La Unión política..., op. cit.

${ }^{69}$ FILIBI, La Unión política..., op. cit. 
en todos los casos (Escocia, Cataluña, Euskadi, Flandes) sólo pueden imaginarse su Estado dentro de la Unión Europea. De hecho, la posibilidad de quedarse fuera se está esgrimiendo por los Estados como la principal amenaza para frenar la secesión. Hasta ahí llega el impacto de la integración europea, ha sido capaz de redefinir para siempre las nociones de soberanía en el continente, tanto entre quienes la disfrutan como entre quienes la reclaman. Se trata de un aspecto de la europeización poco tratado.

En 2014 está previsto que se produzca el referéndum en Escocia sobre su pertenencia al Reino Unido, y en Cataluña se está articulando un gran movimiento nacional con el mismo objetivo. ${ }^{70}$ No se pueden olvidar naciones como la vasca o la flamenca, que presentan características propias y avanzan a su ritmo. Todos estos casos tan diversos, en su conjunto, muestran la necesidad de ofrecer un mejor encaje a estas realidades nacionales, lo que constituye un auténtico reto para la Unión Europea. ${ }^{71}$

\section{La Europa social y el neoliberalismo}

Una de las preguntas contemporáneas más relevantes afecta al papel que el mercado debe jugar en nuestra sociedad, ¿es un medio o un fin? Si se leen los textos y tratados europeos de hace unas décadas parecía quedar claro que la integración económica y la creación de un verdadero mercado europeo constituían medios, herramientas, al servicio de un fin superior: la federación pacífica y democrática del continente. ${ }^{72}$ Hoy, en muchos textos y declaraciones de líderes europeos, esto no queda tan claro.

Esta evolución está directamente relacionada con la evolución ideológica de Europa. Se ha pasado del pacto fundacional entre socialdemocracia y democracia cristiana a un nuevo compromiso entre distintas facciones capitalistas y grupos de interés ${ }^{73}$ donde las versiones más neoliberales casi siempre terminan imponiendo su criterio.

${ }^{70}$ LÓPEZ-JURADO, C., «La secesión de territorios no coloniales y el soberanismo catalán», Revista Electrónica de Estudios Internacionales, n. ${ }^{\circ}$ 26, 2013.

71 VAUBEL, R., «Secession in the European Union», Economic Affairs, Vol. 33, n. ${ }^{\circ} 3$, 2013, pp. 288-302.

72 Es también reseñable el temprano interés de las federaciones sindicales internacionales en la cooperación económica europea a partir de 1922, apoyando la necesidad de una economía europea organizada; a pesar de, cuando discuten cuestiones sociales, enfatizan el papel del marco nacional en oposición al regional (PASTURE, P., «The interwar origins of international labour's European commitment (1919-1934)», Contemporary European History, Vol. 10, n. ${ }^{\circ} 2,2001$, pp. 221-237).

73 APELDOORN, B. van, «La gobernanza socio-económica europea: el futuro del "neoliberalismo de compromiso"», Cuadernos Europeos de Deusto, n. ${ }^{\circ} 35,2006$, pp. 143-173. 
Esta situación cobra más sentido, probablemente, cuando se repasa la forma en que se diseñó la finalización del mercado interior y la Unión Económica y Monetaria. Primero se alcanzó un pacto sobre el mercado interior y sólo luego, sobre la marcha, se incorporó el debate sobre los fondos estructurales y las políticas sociales. Hubo un pacto global que dio lugar a la Unión, pero fue asimétrico: el mercado y el euro son elementos estructurales ${ }^{74}$, irreversibles (salvo sorpresa o catástrofe mayúscula); por el contrario, los fondos estructurales - a pesar de su nombre- deben ser renegociados cada siete años con las perspectivas financieras. Esto ha sido causa de profundas críticas, sobre todo cuando se han podido observar los efectos a medio plazo de tales medidas. Por ejemplo, al tomar de forma conjunta la producción, inversión y crecimiento del consumo, se observa que la creación del euro ha supuesto un aumento de la sincronización de los ciclos económicos en los países centrales y una disminución en dicha sincronización entre las economías periféricas. ${ }^{75}$

La Unión Europea ha recibido muchas críticas, algunas bien fundadas, si bien aquí suele operar otro mecanismo denunciado por Robert Putnam. Este autor observó que a menudo los líderes políticos justifican en base a presiones internacionales la toma de decisiones y políticas impopulares que habrían tomado de todos modos. ${ }^{76}$ Daniel Preece muestra cómo ha sucedido esto en el desmantelamiento progresivo del Estado social en Europa. En el caso de Alemania, gobiernos demócrata-cristianos (Kohl) y socialdemócratas (Schroder) usaron de forma continuada la toma de decisiones comunitaria y el Banco Central Europeo para impulsar el mercado integrado con bajas tasas de inflación que sirviesen mejor a los intereses manufactureros, industriales y financieros alemanes. ${ }^{77}$ Así pues, todas estas decisiones han sido tomadas por gobiernos elegidos, lo que debería incitar a la reflexión. ${ }^{78}$

En cualquier caso, y siguiendo una tendencia de alcance mundial, puede decirse que el modelo socio-económico de la UE ha ido escorándose hacia el

${ }^{74}$ CONTRERAS, A.M.C y KÖLLING, M., «La participación de las CCAA en la negociación de la política de cohesión ¿Ambitions beyond capacity?», Revista de Estudios Políti$\cos$, n. $^{\circ} 161,2013$, pp. 239-278.

${ }^{75}$ LEHWALD, S., «Has the Euro changed business cycle synchronization? Evidence from the core and the periphery», Empirica, Vol. 40, n. ${ }^{\circ}$ 4, noviembre 2013, pp. 655-684.

76 PUTNAM, R.D., «Diplomacy and domestic politics: The logic of two-level games», International Organization, Vol.42, n. ${ }^{\circ}$ 3, 1988, pp. 427-460. En el caso de Europa, ver por ejemplo: RAUNIO, T., «Why European integration increases autonomy within political parties», Party Politics, Vol. 8, n. ${ }^{\circ}$ 4, 2002, pp. 405-422.

77 PREECE, D.V., Dismantling Social Europe: The political economy of social policy in the European Union. Boulder, First Forum Press, 2009.

78 PAULY, Louis W., «Democracy beyond the state? The European dilemma and the emerging global order», A paper prepared for the Carnegie Council on Ethics and International Affairs, New York, 2000,p. 13. 
modelo del capitalismo anglosajón. ${ }^{79}$ Una de sus características más destacadas es la creciente polarización en la distribución de la riqueza y la generalización de la desigualdad. Es llamativo que durante los años de la crisis, la brecha salarial entre los sueldos más altos y los más bajos se ha agrandado, y todo indica que la clase media se va diluyendo. En el caso español, por poner un ejemplo, el salario de los directivos aumentó un 6,9\%, mientras el de los mandos intermedios descendió un 3,8 \% y el de los empleados un 0,4\%. Esta tendencia no es nueva. Un estudio reciente, basado en 80.000 encuestas muestra que el salario medio de los directivos ha subido de forma constante - con la única excepción de 2009- desde 2007, mientras que el resto de trabajadores subió en 2008 y 2009, pero desde entonces no ha dejado de reducirse. ${ }^{80}$ Esta polarización es una tendencia general, pero quienes han tratado de corregirla, como Suiza, se han encontrado con importantes problemas.

No puede extrañar, pues, que el progresivo auge del neoliberalismo haya ido acompañado de una creciente movilización social y política. Desde comienzos de los 80 pueden contabilizarse setenta y cinco huelgas generales en once de los dieciséis países europeo-occidentales, y con una intensidad creciente. Un estudio reciente muestra que en el cuarenta por ciento de los casos los gobiernos hicieron algunas concesiones en respuesta a las mismas. En el diez por ciento, los gobiernos hicieron concesiones importantes. Es interesante observar que los gobiernos más favorables a realizar estas concesiones fueron gobiernos de coalición liderados por partidos de centro o demócrata-cristianos, bastante más que los gobiernos socialdemócratas y conservadores. Resulta curioso que a pesar del declive paulatino en el número de afiliaciones sindicales y del poder negociador relativo de los sindicatos, el grado de éxito con las huelgas generales haya aumentado entre 1980 y 2009. Como posible explicación de esta paradoja, se ha sugerido que los sindicatos han perdido capacidad de presión sobre los empleadores, pero no ha sucedido lo mismo con respecto a los gobiernos. ${ }^{81}$

En el ámbito europeo, el modelo socio-económico de la UE puede entenderse como el resultado de una competición entre distintos modelos de capita-

79 BIELER, A., The struggle for a Social Europe. Trade unions and EMU in times of global restructuring. Manchester, Manchester University Press, 2006.

${ }^{80}$ Evolución salarial 2007-2013. 7. a edición Informe retribuciones. Barcelona, EADA Business School/ICSA. 2014.

${ }^{81}$ HAMANN, K.; JOHNSTON, A. y KELLY, J., «Striking concessions from governments. The success of general strikes in Western Europe, 1980-2009», Comparative Politics, Vol. 46, n. ${ }^{\circ} 1,2013$. Sobre el papel de los sindicatos y sus razones para aceptar la creación de mercados de trabajo duales - empleos fijos y empleos temporales/subempleo-, ver: DAVIDSSON, J.B. y EMMENEGGER, P., «Defending the organisation, not the members: Unions and the reform of job security legislation in Western Europe», European Journal of Political research, Vol. 52, n. ${ }^{\circ} 3,2013$, pp. 339-363. 
lismo: el modelo neoliberal angloamericano, el modelo estatista y las formas más negociadas de capitalismo. ${ }^{82}$ La coalición formada por algunos poderosos grupos de interés financieros e industriales - destacando la European Round Table of Industrialists (ERT) - y los gobiernos de los principales Estados centrales iniciaron la Conferencia Intergubernamental (CIG) sobre la Unión Económica y Monetaria en $1991 .^{83}$ Sólo la reacción liderada por la Comisión Europea de Jacques Delors, y apoyada por otros gobiernos, partidos políticos y grupos de interés, logró añadir una segunda CIG sobre los aspectos más políticos y sociales. ${ }^{84}$ Es interesante recordar que esta no se fusionó con la primera, sino que las dos desarrollaron sus trabajos en paralelo. Ambos procesos de reflexión y negociación sólo se articularon en un único texto integrado en diciembre de 1991, documento que sería el Tratado de la Unión Europea.

Este tratado, firmado en Maastricht en febrero de 1992, abrió un debate sobre la integración europea. Al mismo tiempo que ilusionó a importantes sectores de la opinión pública europea, también inició una tendencia euroescéptica. No pueden olvidarse el voto negativo en el referéndum danés y el voto positivo muy ajustado en Francia. Por otro lado, el aumento de los niveles de desempleo en la UE extendió la idea de que Europa no podía asociarse únicamente con la integración del mercado, olvidando aspectos centrales como el desempleo. ${ }^{85}$ Fruto de este clima de opinión, en la Cumbre de Copenhague de 1993, los Estados instaron a la Comisión a que elaborara un Libro Blanco proponiendo una estrategia para lograr un mayor crecimiento, competitividad y empleo. En la cumbre de Essen de 1994, los jefes de Estado y de gobierno acordaron algunos objetivos para combatir el desempleo y paliar la situación de algunos colectivos particularmente afectados por el desempleo. Estas iniciativas se han interpretado como reacciones a la erosión de los sistemas nacionales de bienestar debida a las regulaciones del mercado interior, lo que supone un reconocimiento de la necesidad de objetivos comunes en el campo social. Sin embargo, los gobiernos se asegura-

82 BIELER, A., op. cit.

83 APELDOORN, op. cit.

84 La articulación de intereses diversos afecta también a los representantes de los trabajadores. Así, los sindicatos de los países europeos apoyan mayoritariamente la estrategia Global Europe para mejorar la competitividad europea en el concierto mundial, mientras que es rechazada con firmeza por los sindicatos de los países emergentes y del Sur (BIELER, A., «The EU, Global Europe, and processes of uneven and combined development: The problem of transnational labour solidarity», Review of International Studies, Vol. 39, n. ${ }^{\circ}$ 1, 2013, pp. 161183; GIRVAN, N., «Social movements confront Neoliberalism: Reflections on a Caribbean experience», Globalizations, Vol. 9, n. ${ }^{\circ}$ 6, 2012, pp. 753-766).

85 LITTOZ-MONNET, A., «Dynamic Multi-Level Governance - Bringing the study of multi-level interactions into the theorizing of European integration», European Integration online Papers, Vol. 14, 2010. 
ron de que estas medidas no fuesen legalmente obligatorias, por una mezcla de desavenencias ideológicas y de miedo a una actividad excesiva de la Comisión en estas materias tan sensibles. ${ }^{86}$

En la CIG que precedió al Tratado de Ámsterdam en 1997, la cuestión del empleo sí fue uno de los puntos centrales de la agenda. Además del Parlamento Europeo y los sindicatos europeos, también hubo delegaciones nacionales que apoyaban la inclusión expresa en los tratados del vínculo entre política económica y empleo. No obstante, otros gobiernos se negaban a iniciar una política europea en materia social. De hecho, los gobiernos conservadores de Francia, Alemania y Reino Unido se negaban incluso a aceptar que la Comisión pudiese elaborar algunas recomendaciones en estos asuntos. ${ }^{87}$ Hubo que esperar a los cambios electorales en Francia y Reino Unido para que el acuerdo fuese posible ${ }^{88}$, a lo que contribuyó también la entrada de los países nórdicos, muy comprometidos con la defensa de sus sistemas de protección social. ${ }^{89}$ La solución finalmente adoptada, dada la imposibilidad de armonizar situaciones tan dispares y con la férrea negativa de algunos Estados a aceptar una legislación europea obligatoria, tuvo que ser, una vez más, otra innovación ${ }^{90}$ : la creación del Método Abierto de Coordinación (MAC).

Este mecanismo se encuentra perfectamente alineado con el proyecto constitucional neoliberal, dentro de un debate constituyente europeo ${ }^{91}$ en el que la alternativa socialdemócrata no deja de retroceder y no parece ha-

${ }^{86}$ SCHÄFER, A., «Beyond the Community Method: Why the Open Method of Coordination was introduced to EU policy-making», European Integration online Papers, Vol. 8, 2004.

${ }^{87} \mathrm{La}$ importancia de la ideología, así como de otras circunstancias personales de los decisores políticos, puede observarse en otros casos. Por ejemplo, en la controvertida propuesta de establecer una imposición fiscal mínima a las empresas en toda la UE (OSTERLOH, S. y HEINEMANN, F., «The political economy of corporate tax harmonization - Why do European politicians (dis)like minimum tax rates?, European Journal of Political Economy, 29, 2013, pp. 18-37).

${ }^{88}$ Este hecho obliga a reflexionar sobre la importancia de las decisiones y elecciones políticas nacionales sobre el desarrollo de la política comunitaria. En alguna medida cuestiona la supuesta incapacidad de las instituciones comunitarias para realizar ciertos avances en las políticas de la UE, porque, en último extremo, tales decisiones están condicionadas por las preferencias de los gobiernos nacionales electos. Así, poco tiene que ver la Comunidad de la década de 1980, con una amplia mayoría socialdemócrata con la de comienzos del siglo XXI, en manos de partidos conservadores, democristianos y liberales. Evidentemente, la política comunitaria no puede - ni debe - ser ajena a estos cambios políticos.

${ }^{89}$ LITTOZ-MONNET, A., op. cit.

90 THRELFALL, M., «The social dimension of the European Union. Innovative methods for advancing integration», Global Social Policy, Vol. 7, n. ${ }^{\circ}$ 3, 2007, pp. 271-293.

91 FILIBI, I. y BELISLE, J.M. (eds.), Constitucionalismo transnacional. Derecho, democracia y economia política en la globalización. Córdoba (Argentina), Editorial de la Universidad Católica de Córdoba, 2010; FERRERO, M. y FILIBI, I., «La contradictoria emergencia de un constitucionalismo transnacional: las dos caras de Jano en Europa», Constitución y democracia, Madrid, Centro de Estudios Políticos y Constitucionales, 2006, vol. 2, pp. 195-211. 
ber otra aún mínimamente articulada. Es una herramienta de corte tecnocrático, que usa cada vez más técnicas procedentes del mundo de la empresa ${ }^{92}$, y que supuso la emergencia de un dualismo institucional que plantea importantes problemas de control democrático y jurídico. ${ }^{93}$

Más allá de este mecanismo concreto, la política social de la UE puede analizarse desde distintos ángulos. Es sorprendente que si se enfoca desde sus programas específicos y su financiación - minúscula en comparación con la de los Estados - o desde el punto de vista legal - cuya competencia se encuentra en el nivel estatal-, los resultados son apenas perceptibles. Por ello, puede decirse que la política social de la UE es, antes que nada, un ámbito por excelencia del discurso político. Respecto a su última innovación, la creación del Método Abierto de Coordinación, hay un amplio consenso en que se trata de un asunto básicamente de discurso. ${ }^{94}$

Las fuentes de estos discursos son los diversos foros y arenas políticas - particularmente a través de los procedimientos del MAC-, la continua producción y adopción de documentos formales por la Comisión y el Consejo, así como la publicación de numerosos textos y propuestas de políticas específicas. Todas estas instancias productoras de discurso deben ser consideradas parte de un proceso abierto de lucha ideológica, «una verdadera batalla librada por ciertas elites que compiten por distintos modelos sociales», ${ }^{5}$ aunque puede identificarse una serie de creencias comúnmente aceptadas por las distintas élites burocráticas comunitarias respecto al enfoque técnico de las cuestiones y a una mayor proximidad ideológica al paradigma de la competitividad que al de la protección social. ${ }^{96}$ De forma coherente con estas dos afirmaciones, se ha comprobado que los gobiernos prestan más atención a las «mejores prácticas» europeas que coinciden con sus preferencias ideológicas. ${ }^{97}$

92 UNCETABARRENECHEA, J., «La política educativa de la Unión Europea con vistas al 2020: ¿una apuesta por la continuidad o por el cambio?», en La nueva Estrategia Europa 2020: Una apuesta clave para la UE en el siglo XXI (IX Premio de Investigación Francisco Javier de Landaburu Universitas 2010), Vitoria-Gasteiz, Eurobask, 2011, p. 174.

93 DE MIGUEL BÁRCENA, J., «La dimensión institucional y democrática de la gobernanza económica europea: el Método Abierto de Coordinación», Cuadernos Europeos de Deusto, n. ${ }^{\circ} 35,2006$, pp. 23-42.

94 BARBIER, J.-C., «Tracing the fate of EU "social policy": Changes in political discourse from the "Lisbon Strategy" to "Europe 2020"», International Labour Review, Vol. 151, n. ${ }^{\circ}$, 2012, pp. 377-399.

95 BARBIER, J.-C., «Tracing the fate...», op. cit., p. 380.

96 RADELLI, C.M. y O'CONNOR, K., «How bureaucratic elites imagine Europe: Towards convergence of governance beliefs?», Journal of European Public Policy, Vol. 16, n. ${ }^{\circ}$ 7, 2009, pp. 971-989.

${ }_{97}$ DELFANI, N., «Expert versus politicians: the role of partisanship ideology in European Union employment policy», Comparative European Politics, Vol. 11, n. ${ }^{\circ}$ 1, 2013, pp. 70-92. 
No obstante, a pesar de que en su mayor parte la política social sigue siendo una competencia en manos de los Estados, el papel del derecho comunitario en este tema no debe ser subestimado. ${ }^{98}$ Es un hecho constatado el efecto destructivo de la gobernanza de la UE sobre los sistemas de protección social existentes en Europa. ${ }^{99}$ Por otro lado, tampoco está claro que los ciudadanos europeos deseen una mayor coordinación de las políticas sociales en el ámbito europeo, ${ }^{100}$ sino, probablemente, una mayor cobertura y eficacia de las políticas sociales, al margen de quién las gestione.

En cualquier caso, el auge del neoliberalismo constituye un factor clave para explicar el actual debate sobre el modelo social europeo. Por una parte, para Vamvakas, este auge ha venido acompañado de una profunda crisis de la socialdemocracia europea, tanto ideológica como en cuanto a sus prácticas y políticas, lo que la ha deslegitimado de forma importante frente a la ciudadanía. La creación del Mercado Interior se ha visto como un factor en este proceso, al alejar el sistema de partidos europeo-occidentales de los partidos basados en la ideología y potenciar partidos atrapa-todo (catch-allparty). Esto habría supuesto la pérdida de centralidad del Estado de bienestar en los partidos socialistas y socialdemócratas, lo que unido al progresivo declive en la afiliación sindical y el auge de una cultura consumista basada en el crédito ha iniciado el declive de la socialdemocracia. ${ }^{101}$

Diversos autores afirman que «la socialdemocracia europea se encuentra a la defensiva tanto en términos de poder político como en el ámbito de las ideas; y ello sucede tanto en los contextos nacionales como en el europeo». Es un hecho que

la socialdemocracia ha perdido poder incluso en sus bastiones tradicionales y en la actualidad no tiene una estrategia política claramente definida para recuperar la hegemonía discursiva en la política y la sociedad. Es lla-

98 BARBIER, J.-C., «Tracing the fate of EU "social policy"...», op. cit., p. 380; SOTIROPOULOS, D.A., «The EU's impact on the Greek welfare state: Europeanization on paper?», Journal of European Social Policy, Vol. 14, n. ${ }^{\circ}$ 3, 2004,pp. 267-284.

99 BARBIER, J.-C. The road to social Europe. A contemporary approach to political cultures and diversity in Europe. Abingdon, Routledge, 2012; SCHARPF, F., «The asymmetry of European integration, or why the EU cannot be a "social market economy"», SocioEconomic Review, Vol. 8, n. ${ }^{\circ}$ 2, 2010, pp. 211-250; FERRERA, M., «National welfare states and European integration: In search of a "virtuous nesting"», Journal of Common market Studies, Vol. 47, n. ${ }^{\circ} 2$, pp. 219-233; BARBIER, J.-C., «EU law as Janus bifrons, a sociological approach to "Social Europe"», en European integration online Papers, Vol. 16, art. 2.

100 MAU, S., «Democratic demand for a social Europe? Preferences of the European citizenry», International Journal of Social Welfare, Vol. 14, n. ${ }^{\circ}$ 2, 2005, pp. 76-85.

101 VAMVAKAS, P., «Maastricht and the death of social democracy: The creation of a consumer culture», Mediterranean Quarterly, Vol. 21, n. ${ }^{\circ}$ 4, 2010, pp. 77-92 
mativo que no ha sido capaz de aprovechar los efectos de la crisis, que han socavado el discurso del neoliberalismo, probablemente porque, al ser coautor de las innovaciones en las políticas económica y financiera desreguladoras de las últimas décadas, ha perdido la credibilidad necesaria. ${ }^{102}$

Según esta interpretación, la crisis actual sólo habría sido el último golpe. De ser así, la socialdemocracia necesita ser reelaborada para adaptarse a una nueva sociedad global en la que las sociedades nacionales ya no definen el ámbito de lo político. ${ }^{103}$

Por otra parte, el debate social se entremezcla con la narrativa y la legitimidad de la integración europea. ${ }^{104}$ Hillebrand y Maass constatan que la vieja narrativa de la integración europea como un proyecto de paz en un continente sacudido por los conflictos y las guerras ya no es suficiente para obtener el apoyo popular. Sin una cohesión política apuntalada socialmente en Europa (Habermas), la diversidad nacional, riqueza cultural y nivel de protección social tan características del continente serán aplastadas entre las dinámicas económicas globales y las nuevas constelaciones de poder geopolítico. ${ }^{105}$

A su vez, las políticas neoliberales, en contra de una opinión extendida, no tienen un efecto homogeneizador en las economías europeas, sino más bien han contribuido a crear distintas variedades de neoliberalismo, lo que sería el resultado, en sintonía con la visión de Apeldoorn, de diferentes compromisos entre las facciones capitalistas dentro de las distintas áreas. En un sentido más general, este hecho también encaja con lo percibido por la academia respecto al impacto del proceso de europeización, la existencia de un impacto de las políticas europeas de manera diferencial por áreas, con una convergencia - cuando existe - sólo por grupos de países o regiones (clustering convergence). ${ }^{106}$

Finalmente, el proceso de la convención constitucional y la posterior negociación que ha desembocado en el Tratado de Lisboa ha ilustrado la divergencia también en los puntos de vista sobre la integración europea, con muchos europeístas frustrados por la deriva neoliberal de la construcción

102 HILLEBRAND, E. y MAASS, G., In search of a new political narrative for a solidaritybased society in Europe. Ten questions about the future of social democracy in Europe, Berlín, Friedrich Ebert Stiftung, International Policy Analysis, October 2011, pp. 6-7.

103 STEVENSON, N., «European 'cultural' Social Democracy: questions of freedom», Cuadernos Europeos de Deusto, n. ${ }^{\circ}$ 48, 2013, p. 87.

104 NEYER, J., «Justice, not democracy: Legitimacy in the European union», Journal of Common Market Studies, Vol. 48, n. ${ }^{\circ} 4$, 2010, pp. 903-921.

105 HILLEBRAND, E. y MAASS, G., In search of a new political narrative for a solidarity-based society in Europe. Ten questions about the future of social democracy in Europe, Berlín, Friedrich Ebert Stiftung, International Policy Analysis, October 2011, pp. 6-7.

106 MARISCAL, op. cit., p. 33. 
comunitaria que se suman a quienes no compartían los ambiciosos objetivos políticos iniciales. ${ }^{107}$ Los resultados negativos de los referéndums holandés y francés mostraron con claridad la fuerza política de la suma de quienes no aceptaron la constitución por ser demasiado neoliberal, demasiado supranacional o demasiado poco federalista. Y el ejemplo más notable de esta divergencia se ha visualizado con el compromiso del primer ministro británico de realizar una consulta al pueblo británico sobre su permanencia dentro de la Unión Europea.

\section{El futuro de Europa, ¿diplomacia o democracia? Hacia una nueva convención}

Es algo admitido que la construcción europea, como se ha visto, fue un proceso gobernado por las élites desde su inicio, y probablemente entonces, con las ruinas de Europa aún humeantes, fue una buena opción. Este método tecnocrático adquirió un elevado nivel de sofisticación y desarrollo, pese a reformas de alcance como la elección por sufragio directo de los miembros del Parlamento Europeo a partir de 1979. Pese a las tradicionales tensiones entre los actores más federalistas (Comisión, Tribunal de Justicia, Parlamento Europeo y algunos gobiernos) y los que oponían cierta resistencia (algunos otros gobiernos), el proceso avanzaba mediante una serie de reglas que regulaban estos conflictos entre las distintas élites y grupos de presión, apoyados por toda una maraña de comités y grupos de expertos que cumplen funciones políticas. ${ }^{108}$

El cambio se originó con el Tratado de Maastricht, por su ambición en temas sensibles como moneda, política económica, política exterior y defensa, asuntos de justicia e interior. El dulce sopor de la opinión pública europea terminó con el inesperado voto negativo en el referéndum danés y la

107 BIRCH, K. y MYKHNENKO, V., «Varieties of neoliberalism? Restructuring in large industrially dependent regions across Western and Eastern Europe», Journal of Economic Geography, Vol. 9, n. . 3, 2009, pp. 355-380.

108 METZ, J., «Expert groups in the European Union: a sui generis phenomenon?», Policy and Society, Vol. 32, n. ${ }^{\circ}$ 3, 2013, pp. 267-278; BOSWELL, C., «The political functions of expert knowledge: Knowledge and legitimation in European Union immigration policy», Journal of European Public Policy, Vol. 15, n. ${ }^{\circ}$ 4, 2008, pp. 471-488; BRADLEY, K.S.C., «Halfway house: The 2006 comitology reforms and the European Parliament», West European Politics, Vol. 31, n. ${ }^{\circ}$ 4, 2008, pp. 837-854; CHRISTIANSEN, T. y LARSSON, T. The role of committees in the policy-process of the European Union: Legislation, implementation and deliberation. Edward Elgar, 2007; FOUILLEUX, E., DE MAILLARD, J. y SMITH, A., «Technical or political? The working groups of the EU Council of Ministers», Journal of European Public Policy, Vol. 12, n. ${ }^{\circ}$ 4, 2005, pp. 609-623; RHINARD, M., «The democratic legitimacy of the European Union committee system», Governance, Vol. 15, n. ${ }^{\circ}$ 2, 2002, pp. $185-210$. 
aprobación por un resultado muy ajustado en Francia, lo que lanzó un amplio debate sobre Europa en todos los países miembros. ${ }^{109}$

Esto supuso también el cuestionamiento serio del tradicional modo de reformar los tratados. La aprobación ciudadana ya no estaba garantizada. Tras dos Conferencias Intergubernamentales que bordearon el fracaso (Ámsterdam, Niza), por la incapacidad de los gobiernos de avanzar con decisión ni de reformar las instituciones y mecanismos de toma de decisiones ante la inminente ampliación hacia el Este, los gobiernos acordaron probar algo nuevo. Se trataba de abrir levemente la participación, con el fin de aumentar la deteriorada legitimidad comunitaria, pero con el control del proceso y la última decisión firmemente en manos de los gobiernos. Este nuevo modo de proceder recibió el nombre de Convención, palabra que se vincula intuitivamente con el parlamentarismo europeo. El mandato que esta convención recibió de los gobiernos era claro y medido, pero su resultado superó con creces las expectativas, lo que inmediatamente la convirtió en un referente a tener en cuenta.

El acuerdo de la Cumbre de Laeken, en diciembre de 2001, para crear una convención que preparase la próxima reforma de los tratados supuso, de hecho, el reconocimiento de los límites de la fórmula clásica intergubernamental (CIG). Aunque la Convención no pudo evitar la sombra de la CIG que culminaría el proceso ni la preeminencia de los intereses de los Estados grandes, el resultado sí fue muy distinto del que podría haberse esperado en una CIG y existe un amplio acuerdo de que constituyó un avance en términos de transparencia, democracia y efectividad en la forma de abordar la reforma de los tratados. ${ }^{110}$

El documento final, una propuesta de Tratado por el que se establece una Constitución para Europa, debe interpretarse en el contexto de otros dos factores contradictorios: por un lado, el surgimiento de un cierto «ethos constitucional» y la posibilidad que los participantes en la Convención tuvieron de «hacer historia»; por otro lado, el fuerte liderazgo, a veces casi autoritario, del presidente del Presidium, Valéry Giscard d'Estaing. ${ }^{111}$

Este liderazgo, que constituyó uno de los principales factores del proceso convencional, se debió al control de la agenda por parte del Presidium y, en particular, de su presidente. Giscard d'Estaing hizo un magistral y astuto uso de tres herramientas. En primer lugar, la limitación del número de enmiendas

109 UNCETABARRENECHEA, J., «Los riesgos de una relevancia excesiva de la competitividad para el proceso de integración europea: una mirada crítica a la Estrategia de Lisboa», Crisis económica y financiera: el papel de la Unión Europea. VIII Premio de Investigación Francisco Javier de Landaburu Universitas 2009, Vitoria-Gasteiz, Eurobask, 2009, p. 127.

$110 \mathrm{ZHAO}, \mathrm{C}$., «Deliberation or bargaining? An analysis on the Convention on the future of Europe», Asia Europe Journal, Vol. 6, n. ${ }^{\circ}$ 3-4, 2008, pp. 427-440.

111 MAGNETTE, P. y NICOLAÏDIS, K., «The European Convention: Bargaining in the

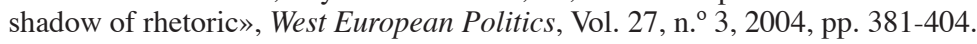


de los delegados de la Convención mediante un férreo control de los tiempos disponibles en cada fase del proceso. En segundo lugar, el proceso para establecer la agenda y la modificación iterativa de enmiendas, consiguiendo que el Presidium controlase habitualmente la enmienda que llegaba a la discusión en sesión plenaria. Finalmente, en tercer lugar, el presidente prohibió las votaciones, obligando a buscar consensos, y esto fue aceptado por la Convención y se convirtió en una norma formal del proceso. ${ }^{112}$

El resultado fue muy bueno, mejor de lo esperado. ${ }^{113}$ Pese a sus limitaciones, ha demostrado una eficacia como mínimo igual a la de los gobiernos para obtener acuerdos complejos y un potencial muy superior de conectar con la ciudadanía y, por lo tanto, de legitimar el proceso de integración.

Por otro lado, la amplitud, profundidad y gravedad de los retos que afronta Europa, hace inviable que la situación pueda enmendarse mediante un simple acuerdo entre los gobiernos. Es necesario repensar Europa, su papel, sus objetivos y su alcance. Los líderes que iniciaron el proceso en 1950 tenían estas ideas claras y también sus razones. En base a ello decidieron avanzar mediante acuerdos entre los gobiernos, y probablemente acertaron. Hoy, el mundo es muy distinto, como lo son las sociedades europeas y la noción legítima de democracia. Los ciudadanos exigen transparencia, rendición de cuentas, participación y sentir que son una parte decisiva del proceso de toma de decisiones colectivas. También exigen mantener unos niveles de protección social y servicios públicos que han sido un referente mundial. Es necesario un proyecto colectivo europeo renovado, ilusionante y que cuente con el apoyo explícito popular. Ya no basta contar con el consenso implícito, es necesario aceptar la participación ciudadana. Es cierto que no se trata de un reto única o principalmente comunitario, ya que estas son las mismas exigencias que deben afrontar los gobiernos en sus respectivos países. La Unión Europea, simplemente, no puede permanecer ajena a esta tendencia general.

La diplomacia puede $-\mathrm{y}$ debe - ayudar. Pero la democracia debe tomar el control del proceso de integración. La convención quizás no sea la solución idónea, pero parece la más razonable. Ya ha sido probada y con unos resultados prometedores. Si bien habrá que mejorar su composición - con más variedad de representantes y con una participación gubernamental más limitada-, parece la mejor propuesta de base para avanzar.

112 TSEBELIS, G. y PROKSCH, S.-O., «The art of political manipulation in the European Convention», Journal of Common Market Studies, Vol. 45, n. ${ }^{\circ}$ 1, 2007, pp. 157-186.

113 ALDECOA, F., Una Europa. Su proceso constituyente 2000-2003. Madrid, Biblioteca Nueva, 2003. 